\title{
Wawqes Pukllas. Prácticas juveniles de escritura quichua (Argentina)
}

\author{
Héctor Andreani \\ Universidad Nacional de Santiago del Estero (UNSE) \\ Consejo Nacional de Investigaciones Cientificas y Técnicas (CONICET)
}

Artículo recibido el 16 de septiembre de 2013, aceptado el 28 de febrero de 2014, versión final el 18 de julio de 2014

\begin{abstract}
Tomando como referencia una experiencia de taller de escritura quichua en una localidad de la provincia de Santiago del Estero (Argentina), donde un grupo de jóvenes bilingües generó diversos tipos textuales en quichua para la elaboración de un libro de su propia autoría, este trabajo describe etnográficamente actitudes, usos y conflictos propios del proceso de la escritura. Este es el marco para reflexionar sobre el rol que juegan las escrituras quichuas, sus funciones e implicancias en estos jóvenes y en su comunidad, dentro de un contexto donde esta lengua nativa (siendo minoritaria respecto del español) no posee una escritura sostenida en prácticas sociales de visibilización pública.
\end{abstract}

\section{Introducción}

Este artículo $^{1}$ explora un tema en exceso marginal y, a largo plazo, sin muchas condiciones sociales de visibilización en zonas de Argentina donde se hablan lenguas indígenas: se trata de su escritura, y ciertas condiciones situadas de producción y circulación de esos escritos. Puede pensarse que se trata de una "preocupación" sobre la escritura en lengua nativa y su posterior "preservación" como efecto inmediato. Sin embargo, ese vínculo no es inherente ni natural (Hornberger, 1995). Para ello, me centraré en la escritura como una práctica social comunicativa, situada, con sus propias condiciones de realización (Vigil, 2004) y sus propias funciones sociales posibles dentro del espacio público y privado.

Este trabajo presenta un caso singular, dentro del contexto de la lengua quichua, hablada en la mesopotamia de la provincia de Santiago del Estero, ubicada en el vértice inferior derecho del cuadrante noroeste de Argentina (NOA), la zona de más influencia andina (ver Fig. 2). A su vez, esta variante santiagueña (denominada como "la quichua" por sus hablantes) es la más sureña y aislada de la familia general quechua.

A partir de una experiencia de taller de escritura quichua con jóvenes bilingües (período 2008-2010), se generaron diversos tipos textuales en quichua para la elaboración de un libro propio. Fue realizado en una localidad rural del departamento Figueroa (Santiago del Estero, Argentina). Esta experiencia no fue singular porque se 
haya logrado el ideal sociolingüístico de la revitalización, sino por la descripción etnográfica de actitudes, usos y conflictos situados, propios de un proceso de escritura en una franja etaria delimitada. Este es el marco para reflexionar sobre el rol que juegan las escrituras quichuas, sus funciones e implicancias en estos jóvenes y en su comunidad, dentro de un contexto donde esta lengua nativa (siendo minoritaria respecto del español) no posee una escritura sostenida en prácticas sociales de visibilización pública. La novedad de este libro es que se trata de la primera obra juvenil en lengua nativa en Argentina, elaborada casi en su totalidad por sus autores bilingües ${ }^{2}$ (ver Fig. $1)$.

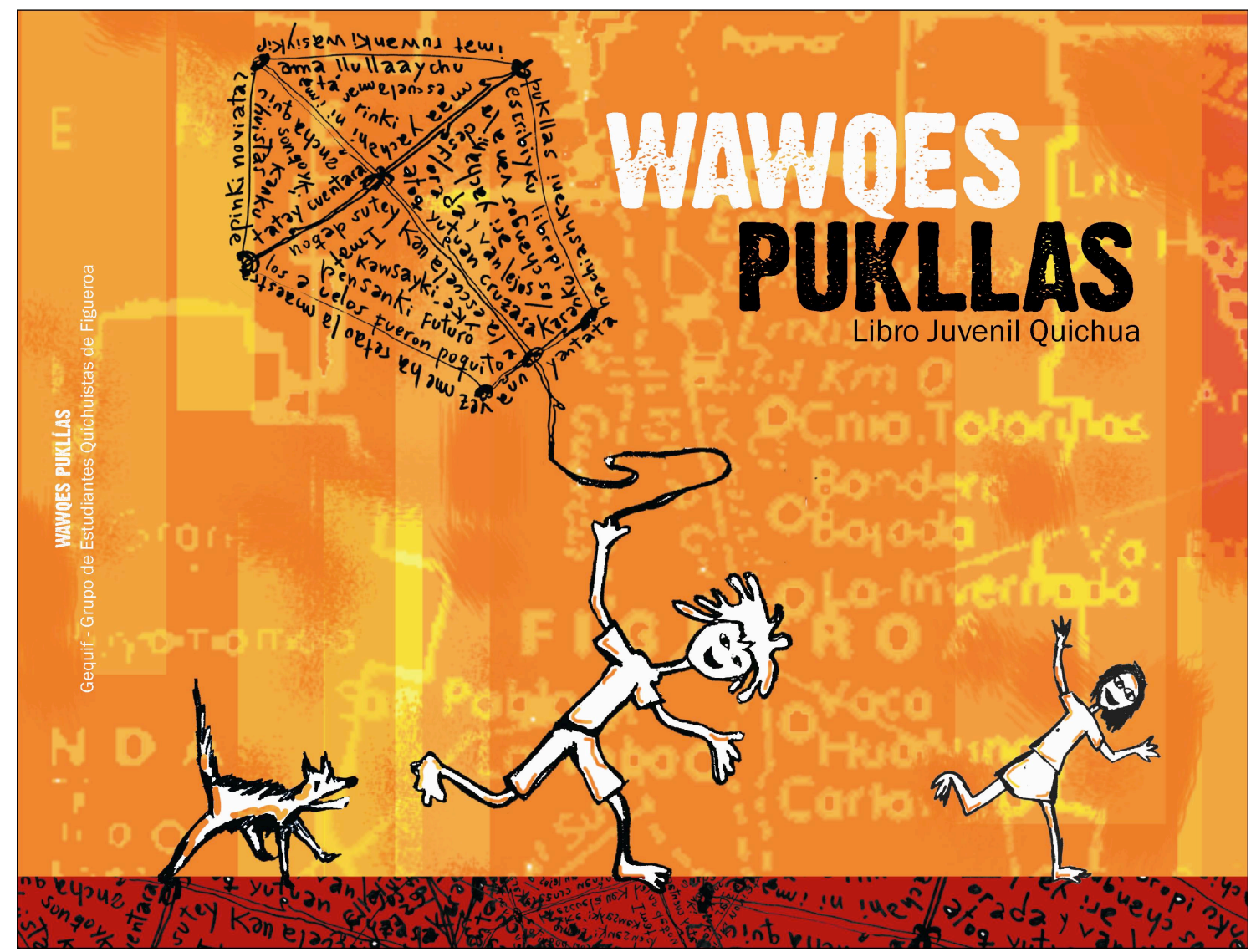

Fig. 1. Tapa del libro juvenil quichua Wawqes Pukllas

Respecto de "la quichua" (denominada así por sus hablantes), sobre un total de 896.461 habitantes en la provincia (INDEC, 2010) hay entre 80.000 y 160.000 bilingües y otros 150.000 en Buenos Aires. Este sector poblacional es un conglomerado étnico (indígenas, afroamericanos, europeos, criollos, árabes, judíos) que se convirtió en su mayoría en bilingüe (Albarracín y Alderetes, 2004), ubicado principalmente en la mesopotamia santiagueña (ríos Dulce y Salado). La quichua es, paradójicamente, una "isla" lingüística que logró mantenerse cuando otras variantes quechuas -y otras 
lenguas- habían desaparecido de la zona NOA. Pero sufrió un proceso de desindianización durante el siglo XIX (Stark, 1985), mediante una subrepticia alianza ruralpolítica local contra el avance modernizador de Buenos Aires (Landsman, 2000), lo cual permitió su mantenimiento como lengua "criolla" en el siglo XX. Se trata de una historia social donde el quichua no entró en el relato nacional como lengua de escolarización, de organismos públicos o medios de comunicación locales. Sumado a esto, muchos bilingües varones son trabajadores migrantes precarizados y sus familias viven en tierras empobrecidas, de modo que se configuró una asociación implícita entre esta lengua y la pobreza.

Las experiencias de escritura en quichua son escasas: hay una tradición discontinua de escritos cuyos orígenes de escritura datan de la década del 30', justo cuando comienza la presión nacional sobre el idioma (cf. Karlovich, 2006, p. 22). Si bien con enormes diferencias, una parte es de orientación didáctica para niños o adultos (Juárez de Paz, 2000; Albarracín, 2009, 2011) y otra menor se enfoca más en literatura ${ }^{3}$ (Tebes y Karlovich, 2006; Tebes, 2009), excluyendo aquí otros estudios descriptivos. Estas experiencias de escritura llevan más de tres décadas de conflictos entre sectores que utilizan alfabetos diferentes ${ }^{4}$. Recurrí a otras experiencias sobre materiales didácticos bilingües para mirar nuestro proceso: un trabajo sistemático colaborativo con niños nahuas (Podestá Siri, 2011); otro es un libro basado en registros etnográficos con niños guaraní-hablantes (Yausaz et al., 2006, Gandulfo, 2007); y otro es un taller como base de la indagación sociolingüística con niños tobas (Hecht, 2010). En este caso se trató de un taller sin intenciones de investigación o diagnóstico sociolingüístico, puesto que mi rol era como "docente" extraclase.

El escenario es una localidad rural del departamento Figueroa. Sobre sus 17.495 habitantes, hay un $52 \%$ de hogares con Necesidades Básicas Insatisfechas, con condiciones de pobreza estructural. De la población mayor de 15 años, el 41,2\% no posee instrucción alguna o no ha completado la instrucción primaria, mientras que el 37,5 posee el primario completo (INDEC, 2005). Estos jóvenes viven en la localidad de Cardón Esquina (100 km. al NNO de Santiago Capital; $1.200 \mathrm{~km}$ al NO de Buenos Aires) con 2.500 habitantes, en su totalidad pequeños horticultores y trabajadores migrantes estacionales (llamados "golondrina"). De los 450 jóvenes que asisten al colegio zonal, la gran mayoría es bilingüe y un número menor se autorreconoce de ese modo sin sentir vergüenza (dada la marginalización histórica hacia "la quichua"). Toda 
la zona es poco productiva, con pequeñas parcelas de agricultura familiar, un bosque xerófilo adaptado al calor extremo y al suelo salitroso, pero también con numerosos conflictos de tierras con empresarios usurpadores, merced a nuevas obras hídricas que permiten nuevas y violentas "expansiones" de la frontera agropecuaria.

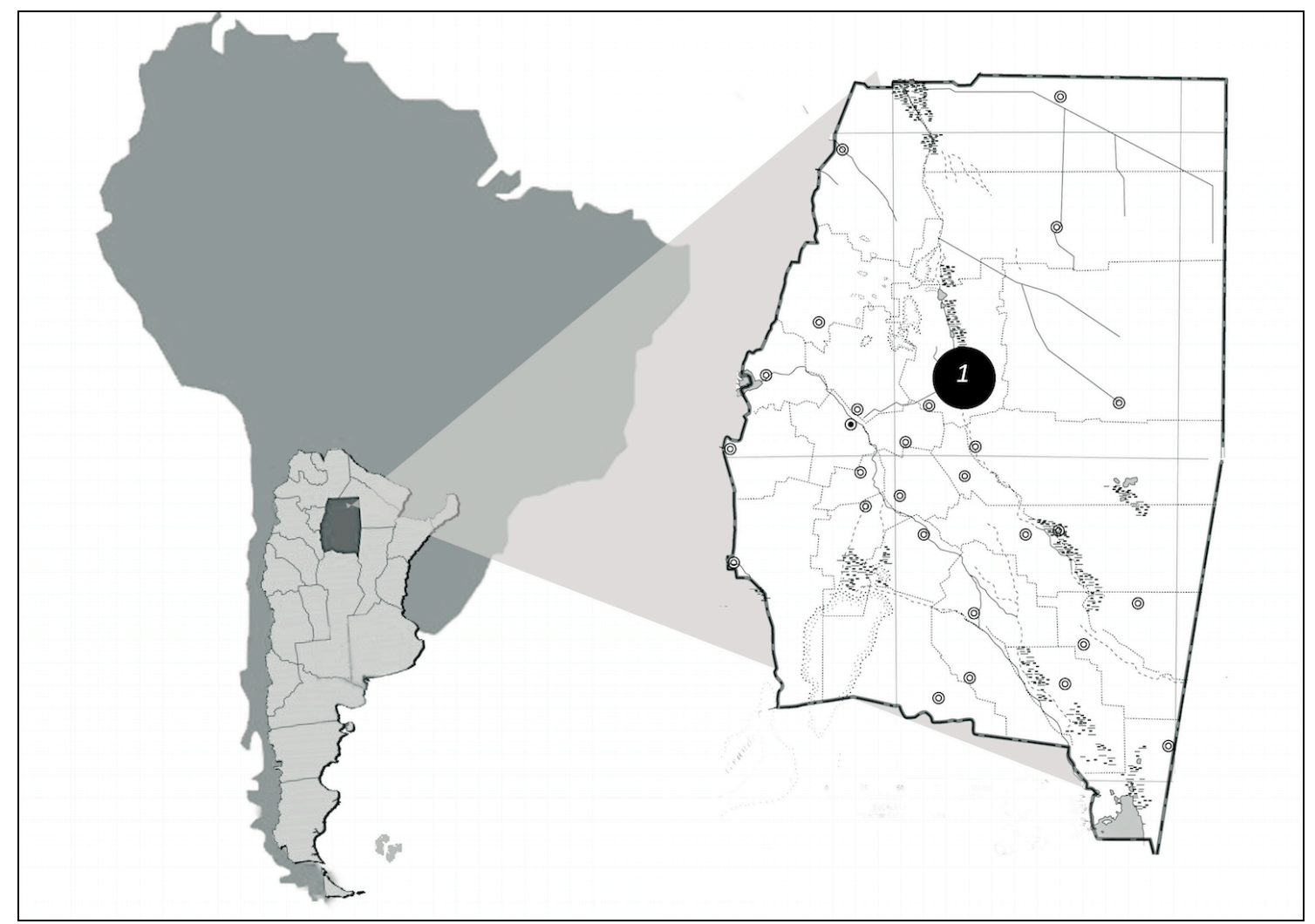

Fig. 2: Provincia de Santiago del Estero, dentro del mapa de Argentina.

En círculo ( $\left.\mathbf{N}^{\mathbf{0}} \mathbf{1}\right)$ : Escenario de estudio: departamento Figueroa y localidad de Cardón Esquina

En el proceso, fui accediendo a varias perspectivas. Hornberger (1995) observa que las prácticas de escritura en lenguas nativas no implican necesariamente una relación directa con la preservación de éstas: para ello, deberán sostenerse en algún tipo de apoyo comunitario. Por su parte, Vigil (2004) propone des-sacralizar la escritura como objeto autónomo, y lograr una "escritura como lo que es, una práctica comunicativa" (cf. 2004, p. 181), basándose en los parámetros culturales concretos donde se asienta como tal. Tomo la distinción de Messineo y Wright (1989) entre funciones receptivas de escritura, donde "los hablantes son meros destinatarios de una información [externa] con contenidos y esquemas de organización culturalmente diferentes pero escritos en su propia lengua", y funciones productivas, donde los usuarios desarrollan "una habilidad no sólo de decodificar información sino también la de generar sus propios textos escritos” (Messineo y Wright, 1989, p. 119). Resulta también útil la clásica perspectiva 
de Voloshinov, distinguiendo entre ideologías subjetivistas -lenguas estéticas, familiares, subjetivas, intimistas- y objetivistas -lenguas gramaticalizables, formalizables e institucionalizables- (1992 [1929]), que permite comprender las actitudes respecto de (y hacia) la escritura quichua que generan ellos mismos. Entendiendo que los procesos bilingües son situados (Unamuno, 2012), gran parte de lo vivido me llevó a describirlos como tácticas (de Certeau, 2000) para entender aspectos por fuera de mi lógica docente.

La propuesta es entender - desde esta experiencia- una forma situada de autoría de la palabra, entendida como la importancia que percibe una persona para expresar su lenguaje-pensamiento; va más allá de una competencia discursiva porque se trata de un proceso dialéctico grupal de toma de conciencia (Requejo, 2004, p. 32), en este caso con jóvenes adolescentes agrupados para una finalidad de escritura.

\section{Metodología y descripción de datos etnográficos}

Van algunas consideraciones previas para objetivar la propia situación. Fui docente en castellano durante seis años en un colegio secundario de Figueroa, que nuclea a toda la población de la zona. Lentamente el quichua se convirtió en un aspecto que interpelaba mi formación docente ${ }^{5}$, con lo cual traté de generar algunas actividades aisladas (juegos matemáticos, un glosario informático quichua, etc.) y sin preparación técnico-teórica que permitiera evaluar mejor el proceso. La quichua aparecía solo como una leve “preocupación" en los demás docentes, pero nunca como "tema pedagógico". Por otra parte, fui problematizando el ideal sociolingüístico-educativo de la revitalización de las lenguas nativas (resabio de la antropología del rescate) sin contemplar variables complejas sobre esa lengua “en peligro". Fue más positiva una perspectiva lúdica sobre todo el proceso (juguemos a escribir), que una perspectiva educativa (el "salvataje" del quichua).

A partir de charlas en el colegio a fines de 2007, fueron surgiendo algunas actividades aisladas de recolección de relatos entre estos jóvenes y yo. Entrevistaban a sus abuelos e iban transcribiendo con mucha dificultad lo relatado: al no haber escrito nunca en su quichua, estos jóvenes registraban con suma dificultad lo relatado por sus abuelos. Esto hizo pensar en un taller extraclase. Son 7 jóvenes bilingües que tenían entre 13 y 17 años en 2008 (todos provenientes de Cardón Esquina) y alrededor de 20 jóvenes que colaboraron indirectamente en los encuentros. Fui observando que ellos 
asociaban implícitamente su escritura a la escolarización del castellano, lo que generó bloqueos para trasladar su quichua (por primera vez) en papel usando el alfabeto castellano.

Un aprendizaje inicial fue que, para llegar a la escritura, no hay que comenzar escribiendo. Después de varias semanas infructuosas de percibir silencios y dudas (el famoso síndrome de la "hoja en blanco" pero con otras implicancias), tuve la idea de llevar grabadores en una primera etapa. Esto supone un registro oral de "su quichua". Lentamente, fueron surgiendo propuestas de trabajo, de tal modo que las actividades no fueran impuestas. Por ejemplo, los jóvenes decidieron agruparse como GEQUIF: Grupo de Estudiantes Quichuistas de Figueroa, y eligieron un cardón (planta cactácea) que los representase como logo. Una forma más eficaz fue la grabación de relatos entre ellos, sin mediar mi presencia. Así, se formó un cuerpo de textos diversos: cuentos del zorro, relatos de aparecidos, accidentes, entrevistas lúdicas entre ellos, etc. El título elegido para el libro fue Wawqes Pukllas (Guillín et al., 2012).

Inicialmente, como coordinador, transcribía los textos en mi ciudad (La Banda, 100 km. de Figueroa), pues los medios informáticos eran insuficientes. Posteriormente, algunos jóvenes propusieron transcribir las grabaciones, y experimentar traducciones de material de castellano a quichua. Casualmente, algunos de ellos pertenecen a familias emparentadas. Esto permitió que, desde el comienzo, se movieran "en pandilla" y asegure cierta cohesión grupal. Las distancias, las altas temperaturas y los horarios hicieron extremadamente dificultosas nuestras reuniones.

Desde el primer momento, decidí “enseñar” un alfabeto pan-dialectal, que se distancia de la normativa castellana y es más económico por basarse en el alfabeto fonético internacional. El problema era el reconocimiento de posvelares oclusivas y fricativas /q/ (wamaq -primero-, sumaq-lindo-, qara -piel-) porque hay una tradición escrituraria castellanizadora (lo exponen como huamaj y ckara). Esto fue inmediatamente reconocido por ellos, porque diferenciaban por sí mismos su oclusiva velar de la posvelar (casa -en español, casa- y qasa-frío-). En el caso de las semiconsonantes $/ \mathrm{w} / \mathrm{o} / \mathrm{y} /$ en márgenes silábicas no percibidas por el oído, por ejemplo tiay (estar), debería ser escrito tiyay. Sin embargo, no tuve en cuenta este tipo de situaciones; simplemente, dejé que ellos reconociesen las grafías que pudieran. No obstante, el iletrismo en esta etapa era un obstáculo, aún en su quichua: por ejemplo, los 
jóvenes escribían y después no podían entender sus propias producciones, puesto que leían como "s" lo que fue escrito con " $\mathrm{j}$ ".

El modo como ellos "aprendieron" el alfabeto quichua fue el siguiente: las primeras digitalizaciones por computadora fueron hechas por mí, e hice circular las hojas impresas en el grupo, para que pudieran "verse" en sus primeros textos grabados. Paralelamente, realizamos sesiones de lectura con algunos textos quichuas (Tebes, 2009) que ya estaban previamente normalizados en el alfabeto pan-dialectal. En el proceso de transcripción, surgían preguntas sobre el uso de tal o cual letra, con lo que tuve que imprimir y poner en circulación un pequeño vocabulario de Alderetes (2001). El uso de la notebook permitió que las digitalizaciones se realizaran en grupo, con cuchicheos y discusiones en bajo volumen sobre cómo escribir determinada palabra. Mi intervención concreta fue normalizar los textos, es decir, estabilizar la lectura respetando todo el sociolecto original de los autores. Si hubiera corregido, habría modificado el sociolecto original por otro sociolecto más normativizado (y prejuicioso de mi parte).

Recién en 2010 estuvimos en condiciones de trabajar con filmadora, grabadora digital y notebook, con la cual terminaron de revisar completamente el libro. Lo novedoso es que pudimos trabajar con estos dispositivos en las casas-rancho de estos jóvenes, en un ambiente de más cotidianeidad. Así, fueron elaborando textos que permiten a la lengua quichua ser usada experimentalmente como lengua de esfera periodística, de investigación o de indagación poética; lo enuncio así porque resulta todavía impensable que "la quichua" se manifieste en medios masivos de comunicación. Pero registro: se trataba sólo de un juego de géneros discursivos.

Una instancia muy interesante fue que dos integrantes comenzaron a elaborar artículos de opinión sobre la zona, íntegramente en quichua, y después traducidos al castellano. Se evidenciaba, de este modo, las posibilidades de expansión del quichua en discursos nuevos y poco habituales. Paradójicamente, esto había sucedido por una tarea propuesta por una docente de castellano en una de las clases del colegio, cuya actividad consistía en escribir un artículo de opinión. Esto fue el estímulo para que ellos se propusieran hacerlo también en quichua, es decir, pensando en el libro.

No pude lograr que se apropiaran de las herramientas de diseño gráfico, precisamente por las distancias y la falta de recursos. Pero sí aportaron la mayoría de las ideas para el diseño del libro, no sólo contactándose con la diseñadora, sino llevándolos 
y hospedando a todos en mi casa numerosas veces. Observamos además que la revisión del material, dada su condición de hablantes competentes en quichua, les facilita enormemente la tarea de comprobación del material en la comunidad, porque evita la saturación de consultas masivas (a numerosos adultos bilingües) para verificar la eficacia de frases complejas que aparecen en el libro. No obstante, en varias "etapas" del proyecto (cada una con sus propias cadenas de encuentros y reuniones) fue posible ver diversos pliegues de corrección, superpuestos en cada etapa, modificando lo anterior. Muchas veces la diferencia entre la primera versión y la última era muy distante. Es decir, ya era una escritura quichua como práctica más segura, y no como el esbozo inicial de frases inseguras en papel.

Pero también hubo otras formas de apropiaciones del castellano para el quichua. Azucena (16 años) decidió traducir un relato de una edición vieja de un diario local (de ideología ultraconservadora), cuya sección refiere al horóscopo, relatos de autoayuda, y consejos para el hogar. El relato hablaba de un hombre que escribió una frase muy emotiva en un cartel, en beneficio de una joven ciega que pedía limosna en la calle, por ende ella recibió muchas monedas. Azucena interpretó ese "relato de marketing" del diario como un relato de solidaridad. Cuando ella decidió leerlo -en quichua y castellano- al grupo, ninguno presentó reparos y les pareció más que interesante. En otro caso, Richar (de 19 años) después de volver de su primer -y duro- trabajo migrante del desflore de maíz, escribió en quichua y castellano su experiencia, y un poema sólo en castellano. Ante la pregunta de por qué no había escrito su poema en quichua, Richar adujo que ya había "demasiado de mi quichua" en el libro, y "que vean bien en castellano (su testimonio)". Aquí hay una seguridad discursiva manifiesta sobre su propia escritura, pero no como "inseguridad" en quichua, sino como una decisión reflexiva de querer escribir en castellano. Hay muchos textos que están expresados con las marcas de oralidad de la "castilla" de la zona. Esto sería percibido por muchos docentes como negativo por la excesiva "cantidad de errores de ortografía", pero es uno de los logros del libro:

“(...) y suri nipusa kara-iAmuy noqap probayt!-Ari, lloqaay, tukuy sachap pasiachisqayki- nipusa kara”.

"Bueno, había venío el avestruz, le había dicho 'probalo en mí' [al bozal]. Y le ha dicho [al zorro] que le suba arriba y que le van a ir a recorrer todo el monte. Le había subío y habían ido a recorrer" (Guillín, et al., 2012, pp. 12-13, mi resaltado). 
Las notas de campo y los registros fílmicos evidencian que nunca realizaron lo que Broide (2009) denomina una modalidad literaria de lectura, sino otro tipo de proceso de lectura-corrección: lectura grupal silenciosa; comentarios murmurados; pequeñas acotaciones al oído; risas disimuladas; alternancias entre leer y enviar mensajes de texto; acotaciones onomatopéyicas en quichua que provocan risas; preguntas frecuentes hacia mí sobre cómo se escribe alguna palabra; una cabeza apoyada en el hombro de otro, mientras miran todos la notebook que uno sólo escribe; el teclear sumamente laborioso; los dedos apoyando la pantalla, siguiendo la línea de lectura; las bromas sobre alguna palabra, que disparaba una pequeña competencia en silencio, a ver quién sabía más, tomando el vocabulario como juez de esas pequeñas contiendas; dibujos circunstanciales referidos a elementos "rurales", con los cuales se diseñó el libro; uso irrestricto del celular en simultáneo con el taller, para comunicar la "novedad" de que estaban en el taller, o "avisar" a algún amigo para que se "llegue" al punto de reunión. Consigno la descripción porque estas formas de lectura, de reunión, de escritura, no son situaciones habituales en los establecimientos educativos locales.

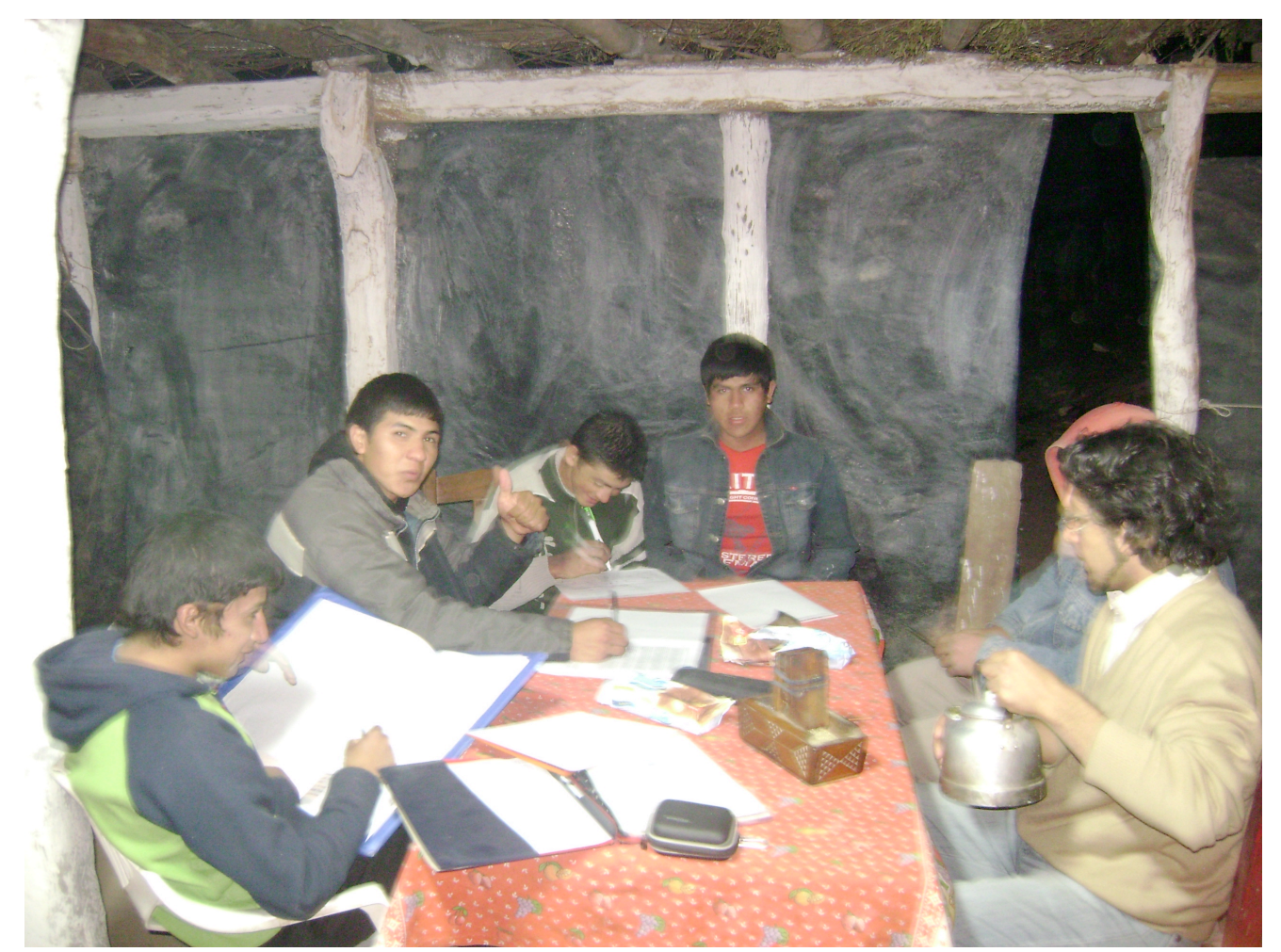

Fig. 2: Encuentro del taller, una noche de invierno de 2010, en la casa-rancho de uno de los jóvenes

Algo sorpresivo ocurrió en 2009, cuando los traje una vez a la ciudad. A la vuelta del viaje, los jóvenes tomaron un transporte local hacia su zona. Les presté la grabadora 
para que sigan transcribiendo unas entrevistas (en quichua) realizadas entre ellos. Después de dos semanas, cuando la grabadora llegó nuevamente a mis manos, descubrí que había carpetas de audio con grabaciones nuevas, hechas en el transporte de viaje, tipo traffic. Fue impactante "escuchar" gritos, carcajadas en volumen alto, y chistes en castellano con muchísimos comentarios y burlas en quichua, con alternancias diversas. Si pudiera "graduar" las seguridades discursivas de estos jóvenes, sería de este modo: en el colegio, casi todos son estudiantes callados, con muy pocas intervenciones en clase; en el taller, hablaban, cuchicheaban entre ellos y hablaban en quichua en mi presencia, sin ningún tipo de restricciones, entre risas, burlas y charlas grupales. Pero en la traffic, había un estado de paroxismo, no sólo de las jovencitas y los muchachos. Lo llamativo es que no había quejas de otros pasajeros (adultos, ancianos), pues todos festejaban las ocurrencias. Se trataba, entonces, de un ambiente de uso quichua plenamente colectivo, vital, sin restricciones. Como categoría local, se trataba de una "joda" plena en la traffic. Discurrían allí cuentos diversos, muchos de ellos "cuentos verdes" (atrevidos), y anécdotas de pobladores ancianos del mismo paraje. De este modo, la trama del zorro pícaro estaba actuando en perfecta sincronía con otros cuentos. Una hiper-trama-picara, "mal hablada", un espacio intersticial narrativo sin coerciones externas.

Valga esta anécdota, para retomar dos cuestiones: primero, un ambiente sin restricciones, de pura "joda" en quichua, donde los muchachos interactuaban en un "delirio" bilingüe, no sólo para los destinatarios inmediatos (en la traffic), sino también hacia mí, pues ellos sabían que yo iba a escuchar esto posteriormente. Segundo, esto era una retribución a un tiempo compartido con ellos. Tardé mucho tiempo en darme cuenta de que yo también estaba incluido en ese ambiente: por eso llevaban la grabadora encendida en todo momento.

\section{Observaciones}

Hay otros aspectos "no-sociolingüísticos" determinantes para el taller. Varios fueron los destinos de estos jóvenes: algunos terminaron su secundario, y están estudiando en el profesorado de educación inicial; otros son trabajadores migrantes, y otros abandonaron el colegio por distintos motivos. En varias ocasiones, alguno de ellos faltaba a los encuentros por las tareas familiares: cargar agua en la "zorra" (un pequeño carro) desde el río, ir a cortar leña ${ }^{6}$ " "flechiar pescados"7 para alimentación propia o de los animales, 
etc. Esas actividades se convirtieron después en temas para el libro. En otras ocasiones, no pude llegar al punto de encuentro por las distancias y el frío; alquilaba una moto que, a veces, no conseguía. Otras veces los mismos muchachos se ofrecieron para llevarme hasta sus casas. En el caso de las jóvenes (15-16 años), muchas veces no pudieron estar en el taller por las distancias, pero también porque era complicado volver de noche a sus casas. Uno de los jóvenes, que tenía 14 años, dejó de estudiar y abandonó el colegio, a causa de su vergüenza por ser demasiado grande corporalmente. Nunca pude convencerlo de que siga estudiando; sin embargo, los encuentros que realizamos en su casa eran impacientemente esperados por él. En otro caso, el más grande de ellos (18 años en 2008) era sumamente inestable para el estudio pues había madurado desde pequeño en situación de abandono familiar, y el más autónomo en sus opiniones, a la vez que el más afable y despreocupado; esto devino un factor de cohesión con los integrantes de menos edad. Consigno estos aspectos aparentemente desconectados de la escritura quichua, pero que fueron determinantes para realizar el taller, y tomar la escritura como objeto central en la vivencia con estos jóvenes.

Las actividades realizadas por estos jóvenes se ubican a medio camino entre las ideologías objetivistas y subjetivistas (Voloshinov, 1992). Respectivamente en nuestro contexto, las que conciben al castellano como propio de instituciones, gramaticalizable y enseñable en el ámbito educativo; y las que actúan sobre la quichua como una entidad minoritaria restringida a la comunicación familiar, afectiva y dentro de los límites de lo íntimo. En el taller había algo más que una ideología subjetivista, pues permitió a un grupo de jóvenes convencerse de que sí se puede generar un material complejo en su quichua, mediante la colaboración activa y constante de un "técnico" que genera un ambiente de participación consciente en el proceso. Y había algo más que una ideología objetivista, porque durante dos años y medio jamás realicé una "clase" de gramática para que los jóvenes aprendieran a leer y escribir, o aprender a "corregirse" en quichua. Como perspectiva "política", resalto que la metodología surgida porta parámetros distintos a lo observado en la educación formal local: el taller ofrece elementos para pensar un laboratorio de investigaciones lúdicas sobre la lengua nativa $\mathrm{y}$, como extensión, como problematización propositiva hacia la enseñanza de la lengua oficial.

Actualmente, fenómenos complejos como el uso de la /q/, /w/ o /y/ en distintas posiciones de sílaba ya no representan un problema en su lectura "normal" en voz alta. Esto problematiza los postulados tradicionalistas que cuestionan el uso de un alfabeto 
pan-dialectal en Santiago, por fuera del alfabeto hispanizante de Domingo Bravo (1956). Además, jamás los hice ingresar en una exógena discusión sobre el uso de alfabetos. Como "dato" antropológico, la metodología de taller permitió refutar el sentido común de la sociedad mayoritaria que categoriza a los adolescentes rurales como sujetos sin un caudal narrativo bilingüe.

Si bien puede ser útil, las grabaciones en grupo focal no funcionaron en gran parte del proceso, pero sí de a dos o más integrantes. Y sobre todo, alejados de mí. Aprendí que nunca debo grabarlos repentinamente, y debo dejar que se apropien de la tecnología como práctica cotidiana en el taller. Sabemos que hay una función productiva por debajo de su aparente silencio o de un "ambiente" que, en rigor, no es una algarabía juvenil explícita. Según el registro etnográfico, son prácticas de lectoescritura que serían percibidas por la mirada docente como una situación de no-lectura, de vergüenza, o incluso de burla (al docente) porque ninguno de estos adolescentes parece estar leyendo ni escribiendo como lo hacen en clase.

En cuanto a otros temas, han traducido material de salud preventiva sobre dengue y animales venenosos. Tanto los cuentos del zorro (muy numerosos e identificables en la zona), y los relatos de espanto (manchachikoq), las adivinanzas (muchas infantiles y otras con tono atrevido), los artículos de opinión (sobre problemáticas de tierra, agua, tránsito en las rutas, falta de viviendas), conviven en el libro con un texto donde un muchacho se le declara a una jovencita mediante un mensaje de texto (SMS) en quichua. Muchos de estos temas facilitaron posteriormente cierta "cotidianidad" de lectura, por los temas locales y estilo en que se tratan. Por otra parte, hemos consensuado un diseño muy variado en cada página, tratando de superar las limitaciones del blanco y negro. Comentamos estas cuestiones pues tratamos de evitar cierta infantilización hacia la producción nativa (D’Angelis, 2007): el libro, por el modo como se fueron concretando las condiciones de producción, se dirige a un público amplio, no sólo restringido al ámbito escolar.

Otro avance fue la problematización de un criterio purista hacia el quichua. Hay textos con palabras castellanas que sí tienen su equivalente en quichua, y los jóvenes no lo usan. Esto no significa vergüenza ni desconocimiento, sino que nuestra tarea fue no abusar del diccionario quichua: si surgía alguna palabra quichua que ellos desearan agregar, lo hacían. Por ejemplo, en una adivinanza sobre un pajarito: "apin alasniyoq y mana paan" (tiene alas y no vuela). Likra es "alas" en quichua, pero ellos dejaron su 
equivalente castellano. Este tipo de decisiones reflexivas fueron muy frecuentes en todo momento. Lo importante fue respetar sus propios tiempos y seguridades discursivas, en algo que no es traducción literal o indirecta, sino otra versión de lo narrado en su otra lengua. Al menos, en este contexto, la literatura como disparador (Solé, 1998) no fue una herramienta eficaz. Había que despojarse de "lo literario" como factor de bloqueo. El único género que activó producciones fue la entrevista: si bien se trata de un evento comunicativo artificial (cf. Briggs, 1986), en este caso era un juego espontáneo que los predispuso a asumir roles sociales distintos en cada uno ${ }^{8}$.

Una de las reflexiones planteadas es: ¿Qué sucede posteriormente con esta práctica, una vez que concluye como "proyecto" educativo? Su escritura quichua no "fluye" naturalmente porque no hay otros dispositivos de estímulo ni hábitos cotidianos. No obstante, mi pregunta no es adecuada porque, repito, la relación entre escrituralidad y el mantenimiento de una lengua minorizada no es inherente; para ello, la escrituralidad debe sostenerse en algún tipo de parámetro comunitario (Hornberger, 1995). Si bien históricamente la mayoría de textos quichuas fue generada por noquichuahablantes (una función receptiva), la experiencia de estos jóvenes puede llegar ser más compleja que la mera "traducción" de un texto castellano a quichua -o viceversa- porque descubrimos diversas formas. Algunas podrían acercarse a la creencia de que existe la traducción simétrica (entre lenguas), pero también hubo situaciones de estabilidad entre su fluir de escritura quichua, y mis intenciones de que escriban en quichua.

Nuestra solapada (e irreflexiva) perspectiva "militante" sobre las lenguas nativas y su escritura, puede opacar el hecho de que -por ejemplo, en estos jóvenes- se trata de procesos inconclusos, a veces con muchos bloqueos, pero que se van desarrollando sin tener que explicitarse necesariamente como resistencias (Requejo, 2004, p. 263). Esa autoría puede no ubicarse en la escritura o en los textos, sino en el complejo proceso no siempre visible- que los sostiene y les da posibilidades de emerger (Ibid., p. 125). La experiencia y el registro en terreno piden algunas categorías-puente que permitan interpretar mejor todo el proceso: pienso que la autoría refiere más a mis propios fines idealizados en esa acción compartida, que las acciones definidas que estos jóvenes decidieron realizar conmigo. En sentido certoniano, diría que ellos terminaron realizando sus propias tácticas lecto-escriturales como respuesta a mis estrategias de “docente". Lo cierto es que algo se "activó" en estos jóvenes durante dos años, pero se 
trató más de ciertas fluctuaciones discursivas antes que una autoría -definida y deliberada- en ellos. Digo fluctuaciones en tanto una trayectoria muy particular del proceso (descrito en este trabajo) en cada uno de ellos; y discursivas en tanto usos "nuevos" y situados de discursos y de lengua/s.

Todas las fluctuaciones discursivas de estos jóvenes, y la ausencia de referencias "políticas" hacia el quichua en su libro, pueden entenderse mejor a partir de la propia historia social local. "La quichua", desde hace más de medio siglo, no se configuró como marcación política de los subalternos ni de la hegemonía. Después del proceso decimonónico de des-indianización, el quichua no entró en el pacto de modernización nacional (como lengua medial, administrativa o educativa); solamente emergió como una aceptable marcación folklórica de las élites, pero configurando su compleja trama oral por fuera del imaginario hegemónico (Andreani, 2014). Se trata de un bilingüismo gradualmente impuesto durante el siglo XX, a raíz de una reciprocidad hegemónica entre Estado de bienestar que otorgó nuevas identidades ciudadanas, políticas y laborales, y una comunidad que "devolvió" con fuerza de trabajo, lealtad y pacificación (Escolar, 2007). Históricamente, la mayoría de textos quichuas fue generada por noquichuahablantes (es decir, como prácticas exógenas de literatura, ensayo y gramáticas). Por ello, "la quichua" nunca fue una marcación estratégica de etnicidad política (sea en el campesinado o en etnogénesis indígenas recientes), y tampoco lo fue en las prácticas gubernamentales. Este marco permite entender por qué "la quichua" no iba a aparecer como resistencia lingüística en estas escrituras juveniles. 


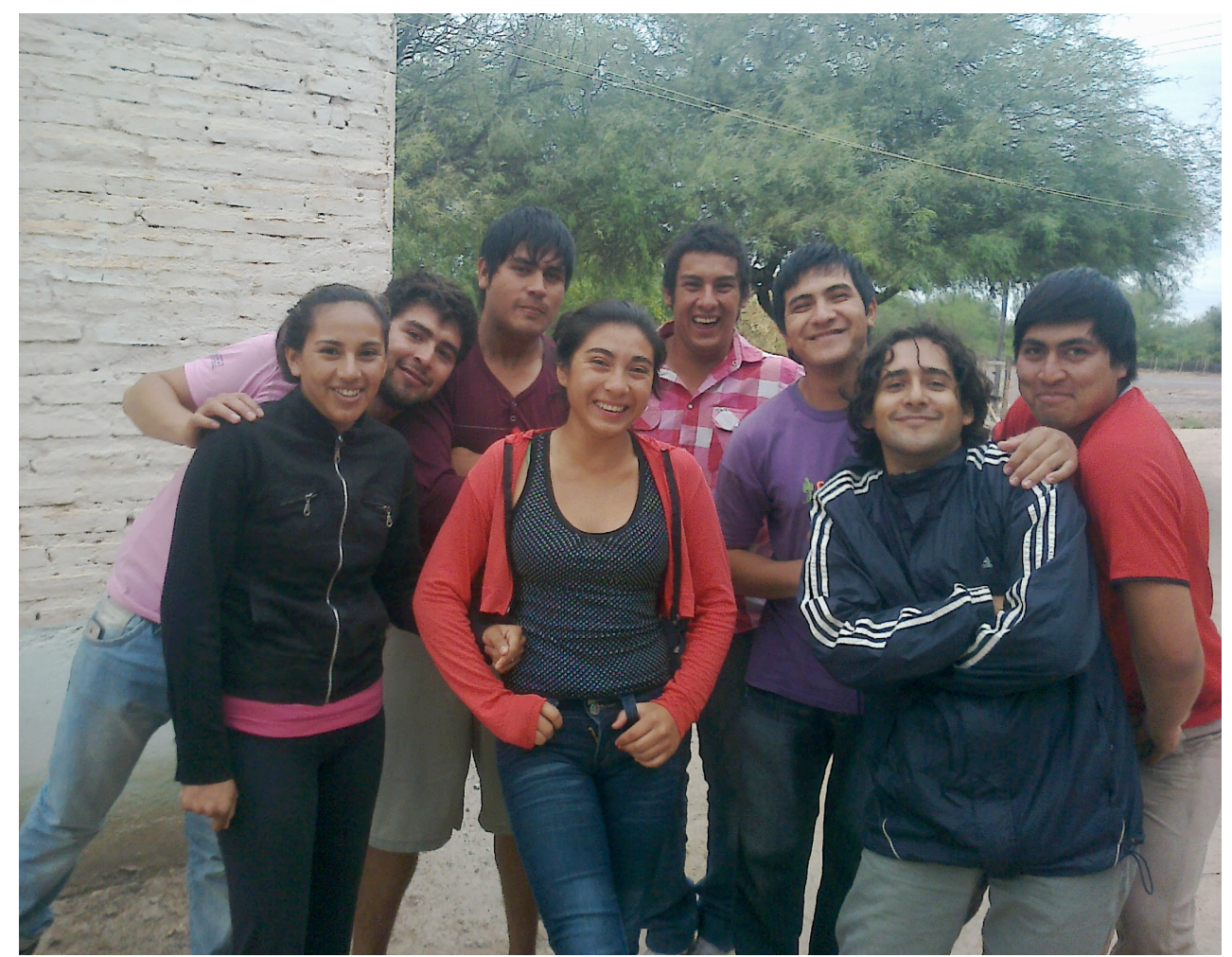

Fig. 4: Grupo del taller en 2013. Adelante: Mariela, Azucena, Héctor (coordinador). Detrás: Elías, César, Orlando, Richar y Cristian.

Otra evidencia de esta historia de minorización puede observarse en ciertas actitudes de recepción del libro. En 2013, muchos fueron distribuidos en dos escuelas primarias, un colegio y un profesorado de la zona. Algunos de sus docentes cuentan cómo "los changuitos $^{9}$ se hicieron de los libros, ya es de ellos"; en otra escuela los alumnos de 7 mo grado hicieron una colecta para comprar más libros y llevarlos a sus casas; en el profesorado, son leídos como disparadores de discusiones en clase. No obstante, en algunos adultos pueblerinos hubo críticas hacia el quichua "mal escrito" de estos jóvenes (aunque todos los textos hayan portado numerosas "capas" de corrección). Con estos casos, pude comprender que es difícil un consenso entre hablantes nativos cuando se trata de "expresiones" escritas en esa lengua, teniendo en cuenta que la mayoría de estos pobladores (con excepción de escasísimas situaciones) jamás había visto al quichua escrito. Aunque los textos estén bien o mal expresados, los argumentos se basaban en un purismo quichua, casi siempre contradictorio entre esos mismos receptores adultos. En los niños y jóvenes, esto no sucedió porque solo querían su libro para mostrarlo a sus familias, como un fetiche. Consignamos estas situaciones posteriores al taller, para dar cuenta de que el imaginario sociolingüístico local sobre la 
lengua nativa (a partir de lo que suscita su escritura "pública") es más heterogéneo de lo que se supone.

Algunos estudios andinos proponen una planificación lingüística más de terreno, retomando los parámetros de las prácticas cotidianas y sin restringirse exclusivamente al ámbito educativo (cf. Sichra, 2005; Vigil, 2004). Posiblemente Wawqes Pukllas como estrategia no logre efectos "escolarizados" de lectura en la población, pero ellos se propusieron "hacer circular" los libros de un modo singular: nada de publicidades, ni mesas paneles, ni notas periodísticas. Considero que se trata de una perspectiva nativa de política lingüística, aplicado a (o desde) sus propias producciones escritas, pero que también puede comprenderse desde la historia de minorización hacia el quichua descrita anteriormente.

Algunos aspectos descritos de esta experiencia grupal pueden enriquecer o problematizar parámetros de lo que el Estado sugiere o impone en sus programas educativos como interculturalidad y bilingüismo. Después de más de medio siglo de modernización nacional que configuró de modo subalterno al quichua (y la subjetividad de sus hablantes), los pormenores de la elaboración reciente de un libro juvenil, aunque aislado, es un fuerte indicio para entender la histórica asimetría sobre estas poblaciones plurilingües de Argentina. Un grupo de jóvenes aceptó el desafío de escribir en una lengua donde su subjetividad se sentía más cómoda, a pesar de una historia social complicada. Con este caso, el artículo trató de aportar a los estudios etnográficos sobre nuevos usos plurilingües que ocurren en procesos situados de nuevos conflictos y creaciones.

\section{Bibliografía}

Albarracín, L. (2009). La quichua. Gramática, ejercicios y vocabulario (Vol. I). Buenos Aires: Dunken.

Albarracín, L. (2011). La quichua. Gramática, ejercicios y vocabulario (Vol. II). Buenos Aires: Dunken.

Albarracín L. y Alderetes, J. (2004). El Quechua en Argentina: El caso de Santiago del Estero. International Journal of the Sociology of Language, 167, 83-93.

Albarracín L.I., Tebes M. y Alderetes J. R. (Comps.) (2002). El Quichua Santiagueño por Ricardo J.L. Nardi. Buenos Aires: Dunken.

Alderetes, J. (2001). El quichua de Santiago del Estero: Gramática y vocabulario. San Miguel de Tucumán: Universidad Nacional de Tucumán.

Andreani, H. (2014) Quichuas, picardias y zorros. Conflictos y tácticas en una comunidad bilingüe. Santiago del Estero: Editorial de la Universidad Nacional de Santiago del Estero (EDUNSE). 
Bravo, D. (1956). Cancionero Quichua Santiagueño. Contribución al estudio de la poesía quichua santiagueña. Tucumán: Universidad Nacional de Tucumán.

Briggs, C. (1986). A sociolinguistic appraisal of the role of the interview in social science research. Cambridge: Cambridge University Press.

Broide, M. (2009). ¡El pomberito ha muerto! ¡Qué viva el pomberito! Narración, experiencia y literatura en dos escuelas correntinas. En Palleiro, M. I.; Fischman, F. (comps.) Dime cómo cuentas: narradores folklóricos y naradores urbanos profesionales (pp. 157-179). Buenos Aires: Miño y Dávila.

D’Angelis, W. (2007). Cómo nasce e por onde se desenvolve uma tradiçao escrita em sociedades de tradiçao oral? Campinas, SP: Curt Numendajú.

De Certeau, M. (2000) [1990]. La invención de lo cotidiano: Las artes del hacer. México D.F.: Universidad Iberoamericana.

Escolar, D. (2007). Los dones étnicos de la nación. Identidades huarpe y modos de producción de soberanía estatal en Argentina. Buenos Aires: Prometeo.

Gandulfo, C. (2007). Una investigación antropológica como fuente para la elaboración de un libro de lectura destinado a niños de primer año. En: IV Congreso Nacional y I1 Internacional de Investigación Educativa. Facultad de Ciencias de la Educación, Universidad Nacional del Comahue.

Guillín, C.; López, O.; Torrez, A.; Pérez, M.; Guillín, R.; Barraza, E.; Guillín, C. (2012). Wawqes Pukllas. Libro juvenil quichua. Buenos Aires: En el aura del sauce.

Hecht, A. C. (2010). Todavía no se hallaron hablar en idioma. Procesos de socialización lingüística en niños en el barrio toba de Derqui (Argentina). Lincom Europa.

Hernández, J. 2007 [1872]. Martín Fierro (Traducción al quichua y edición bilingüe por Sixto Palavecino). Santiago del Estero: El Liberal.

Hornberger, N. (1995). Escrituralidad, preservación de la lengua y derechos humanos lingüísticos: tres casos ilustrativos. En: Alteridades, 5, (10), 67-78.

Juárez de Paz, I. (2001). Lingüistica regional Quichua santiagueño-Castellano. Santiago del Estero: Talleres El Liberal.

Instituto Nacional de Estadísticas y Censos (INDEC). En Línea: http://www.indec.mecon.ar/

Karlovich, A. (2006). De la oralidad a la escritura. Estudio preliminar. En: Tebes, M.; Karlovich, A. (coords.), Sisa Pallana: antología de textos quichuas santiagueños (pp. 15-35). Buenos Aires: Eudeba.

Landsman, M. E. (2000, octubre). La lengua en la dominación política (del Quichua de Santiago del Estero). Ponencia presentada en VI Congreso Internacional de la lengua Quechua. Santiago del Estero, Argentina.

Messineo, C., y Wright, P. (1989). De la oralidad a la escritura. El caso Toba. Lenguas Modernas, 16, 115-126.

Podestá Siri, R., con niñas y niños nahuas (2011). Mi pueblo en fotografías. El mundo de las niñas y niños nahuas de México a través de sus propias imágenes y palabras. Puebla: Benemérita Universidad Autónoma de Puebla.

Requejo, M. I. (2004). Lingüistica Social y autorías de las Palabra y el Pensamiento: Temas de debate en psicología social y educación. Buenos Aires: Ediciones Cinco.

Sichra, I. (2005). El bilingüismo en la teoría, la idealización y la práctica: ¿dónde lo encontramos? Una reflexión sociolingüística sobre el contacto de lenguas. En: $V$ 
Encuentro de Lenguas Aborígenes y Extranjeras. Salta, Universidad Nacional de Salta.

Stark, L. R. (1985). Historia del Quichua de Santiago del Estero. En H. M. Klein y L. R. Stark (eds.) South American Indian Languages: Retrospect and Prospect (pp. 732-752). Austin (Texas): Universidad de Texas.

Solé, I. (1998). Estrategias de lectura. Barcelona: Graó.

Tebes, M. C. (2009). Castañumanta Yuyayniy. Ni los años ni la distancia. Buenos Aires: Dunken.

Tebes, M. y Karlovich A. (2006). Sisa Pallana. Antología de textos quichuas santiagueños. Buenos Aires: Eudeba.

Unamuno, V. (2012) Plurilingüismo y educación intercultural bilingüe: miradas en cruce. En V. Unamuno, A. Maldonado, Prácticas y repertorios plurilingües en Argentina (pp. 235-249). Grup de Recerca en Ensenyament i Interacció Plurilingües (GREIP). Buenos Aires: Los autores.

Vigil, N. (2004). Acciones para desarrollar la escritura en lenguas indígenas. Glosas didácticas, $N^{o} 12,174-183$.

Voloshinov, V. N. (1992). El marxismo y la filosofía del lenguaje. Los principales problemas del método sociológico en la ciencia del lenguaje. Madrid: Alianza Editorial.

Yausaz, F.; Velozo, M.; Salazar, B.; Gandulfo, C.; Fernández, L.; Agnoletti, P. (2006). Martín y Ramona. Corrientes: Instituto Superior San José.

\section{Agradecimientos}

Este artículo es posible en el marco de una beca de posgrado del Consejo Nacional de Investigaciones Científicas y Técnicas (CONICET). Agradezco la lectura de Virginia Unamuno (UBA-CONICET) y su revisión del resum. A Eduardo Acuña y María J. Rondano por el abstract. A los jóvenes autores del libro, que leyeron en su versión borrador. Agradezco las observaciones de los evaluadores anónimos, que enriquecieron notablemente este texto. Cualquier error es mi responsabilidad.

\footnotetext{
${ }^{1}$ Wawqes Pukllas (Guillín, et al., 2012), en quichua "Hermanos jugando", título del libro juvenil referido en este trabajo. El artículo ha sido elaborado con el consentimiento de los jóvenes integrantes del grupo, también para usar sus nombres reales en epígrafes y cuerpo del artículo.

${ }^{2}$ La "castilla" es la denominación nativa para la variedad rural santiagueña del castellano, en constantes transferencias diversas con "la quichua".

3 Un libro marcó una bisagra en "literatura" quichua: Sisa Pallana, antología de textos quichuas santiagueños (Tebes y Karlovich, 2006) una antología fundamental que no fue pensada como libro didáctico de lectura escolar, aunque pueden adaptarse muchos fragmentos con tal fin. Por otra parte, la versión quichua de la obra gauchesca Martín Fierro realizada por Sixto Palavecino (Hernández, 2007), financiada desde la secretaría provincial de cultura, pero con circulación nula en un público bilingüe rural. Otro libro determinante, Castañumanta Yuyayniy, ni los años ni la distancia, de Mario Tebes (2009) es el primer libro en quichua de autor único en Argentina: la novedad es que se trata de textos escritos íntegramente en quichua, y traducidos al castellano por un colaborador. Probé distribuyendo algunos ejemplares en estos jóvenes, y la lectura fue más que amena en numerosas ocasiones. Tebes, fallecido en 2009, proviene del dpto. Figueroa, la misma zona donde viven estos adolescentes.

${ }^{4}$ Hay toda una tradición conflictiva entre alfabetos; uno es un alfabeto (signografía) elaborado con la normativa castellana, distanciado de la familia quechua y defendido por tradicionalistas urbanos hispanófilos (Bravo, 1956); el otro es un alfabeto pan-dialectal (Alderetes, 2001; Albarracín et al. 2002; Tebes y Karlovich, 2006; Albarracín, 2009) proveniente del círculo internacional de lingüistas, con intención estandarizadora y autónoma respecto del castellano, y particularizado a cada sociolecto. Mi postura fue en todo momento aplicar el alfabeto pan-dialectal: como muestro en este artículo, las críticas
} 
de los tradicionalistas es infundada, puesto que se requirió de un tiempo relativamente breve para que se acomodaran a una lectura en "tiempo normal" con el alfabeto pan-dialectal.

${ }^{5}$ Era muy evidente la disparidad entre el perfil de alumnos clase media-urbana (impartido desde el profesorado) y los alumnos reales; pero sobre todo mi background de enseñanza dirigida a adolescentes clase media urbana. Los "futuros profesores" no somos conscientes de que nuestra formación lingüística se estructura a partir de una perspectiva de clase.

${ }^{6}$ Hay fotos de ellos mismos en el rol habitual de "hacheros", como imágenes de enganche para lectores locales.

${ }^{7}$ Hay un cuento con gran intensidad de picardía (como tantos en la zona) donde un pescador (flechiador) ganaba una apuesta a sus amigos para ver quién pescaba más.

${ }^{8}$ En un caso, el entrevistado "hacía como que" volvía de Buenos Aires después de un extenso tiempo de trabajo, y que había estado en la casa de gobierno con la presidente, charlando con ella de cosas "santiagueñas".

9 "Changuitos", categoría ampliamente usada en el noroeste argentino (NOA) para referirse a los niños.

\section{Referencias del autor:}

Héctor Andreani es becario doctoral del Consejo Nacional de Investigaciones Científicas y Técnicas (CONICET), con asiento en el Instituto de Estudios para el Desarrollo Social (INDES) de la Universidad Nacional de Santiago del Estero (UNSE). Es licenciado en letras (UNSE), doctorando en antropología en la Universidad Nacional de Córdoba (UNC) y fue profesor rural en lengua. Autor de relatos de reflexión sociolingüística Figuritas quichuas (En el aura del Sauce, 2013), y la etnografía Quichuas, picardía y zorros (EdUNSE, 2014). Actualmente explora procesos educativos, migracionales y narrativos de la población bilingüe (quichua-castellano) en Santiago del Estero, Argentina. Es miembro del consejo de la revista Trabajo y Sociedad (INDES-CAICYT).

Email: hectoralfredoandreani@yahoo.com.ar

Para citar este artículo:

Andreani, H. (2014). Wawqes Pukllas. Prácticas juveniles de escritura quichua (Argentina). Bellaterra Journal of Teaching \& Learning Language \& Literature, 7(4), 38-56. 